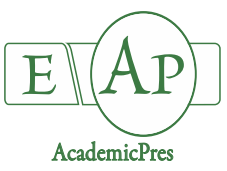

Kruczek A et al. (2021)

Notulae Botanicae Horti Agrobotanici Cluj-Napoca

Volume 49, Issue 2, Article number 12271

DOI: $10.15835 /$ nbha 49212271

Research Article

\title{
Micropropagation, rooting, and acclimatization of two cultivars of goji (Lycium chinense)
}

\section{Arleta KRUCZEK ${ }^{1}$, Marcelina KRUPA-MAŁKIEWICZ ${ }^{2 *}$, Ireneusz OCHMIAN ${ }^{1}$}

\author{
${ }^{1}$ West Pomeranian University of Technology Szczecin, Department of Horticulture, Stowackiego 17 Street, $71-434$ Szczecin, \\ Poland; ka21499@zut.edu.pl; iochmian@zut.edu.pl \\ ${ }^{2}$ West Pomeranian University of Technology Szczecin, Department of Plant Genetics, Breeding and Biotechnology, Stowackiego 17 \\ Street,Szczecin,Poland; mkrupa@zut.edu.pl ('corresponding author)
}

\begin{abstract}
In recent years, Lycium chinense (goji) has become increasing popular because of its public acceptance as a "superfood". Hence, the present study aimed to develop a rapid production technology by using in vitro culture to produce plants with high health value, throughout year and in desired quantities. A micropropagation protocol for growing $L$. chinense 'No 1' and 'New Big' cultivars was developed. The explants were grown on MS medium supplemented with different concentrations of meta-Topolin $\left(0.4-0.8 \mathrm{mg} \mathrm{L}^{-1}\right)$, and WPM and RA without plant hormones. Among the tested combinations, the maximum regeneration rate (9597\%) with the mean shoot length of 3.53-4.12 cm and mean shoot number of 1.42-1.58 ('No 1' and 'New Big', respectively) was recorded for plants grown on MS with $0.6 \mathrm{mg} \mathrm{L}^{-1} \mathrm{mT}$ and WPM. For in vitro rooting, healthy roots $(4.71-4.91 \mathrm{~cm})$ were obtained on MS with the addition of $20 \mathrm{ppm}$ chitosan. A maximum of $70-80 \%$ plantlets ('No 1' and 'New Big', respectively) regenerated on the medium with chitosan were successfully acclimatized and established in the mixture of $90 \%$ peat and $10 \%$ perlite under field conditions.
\end{abstract}

Keywords: acclimatization; chitosan; in vitro and ex vitro rooting; meta-Topolin; superfood wolfberry

\section{Introduction}

In recent years, there has been a growing tendency to use products of plant origin in medicinal, cosmetic, and therapeutic products. This is related to the increasing public awareness of long-term consequences of the use of chemical compounds on health and environment. Hence, more attention is being focused on the use of certain fruits and plant compounds that have been traditionally used in folk medicine for many years. One of such plants is goji.

Lycium chinense (Solanaceae), commonly known as goji berries or wolfberries, is considered one of the healthiest foods in the world because of its highly beneficial nutritive and antioxidant properties (Kruczek et al., 2020a). Goji fruits contain various nutrient, such as polysaccharides, organic acids, phenolic compounds, and antioxidants with high biological activity (Wojdyło et al., 2018; Sá et al., 2019; Kruczek et al., 2020a). Hence, it is frequently called as "red diamonds". Goji is the most powerful antioxidant of all the existing foods

Received: 15 Feb 2021. Received in revised form: 10 Jun 2021. Accepted: 10 Jun 2021. Published online: 23 Jun 2021.

From Volume 49, Issue 1, 2021, Notulae Botanicae Horti Agrobotanici Cluj-Napoca journal uses article numbers in place of the traditional method of continuous pagination through the volume. The journal will continue to appear quarterly, as before, with four annual numbers. 
in the world and contains more carotene than any other food known to date (Tabăra, 2017). These berries have been used in herbal medicine and as a health food for thousands of years. Goji is grown in areas that have not been polluted by civilization or pesticides for centuries, particularly in China, Southeast Asia, Europe, and North America (Kulczyński and Gramza-Michałkowska, 2016; Sá et al., 2019; Kruczek et al., 2020a).

Because of its high nutraceutical and pharmaceutical value (Dănăilă-Guidea et al., 2015; Kruczek and Ochmian, 2016; Kruczek et al., 2020a), the production of goji has been rapidly increasing. Wolfberry plants are traditionally propagated trough their seeds and usually encounter problems related to sexual propagation, especially low germination, lack of clonal expansion, and irregular agronomical performance (Silvestri et al., 2018). Clonal micropropagation by in vitro culture is the best alternative to overcome these barriers and has great potential for rapid multiplication and production of high-quality plant material. Hence, it is crucial to develop and optimize the technology of rapid production by in vitro culture to produce plants with high economic and medicinal value, such as goji berries, throughout the year and in desired quantities. Regeneration capacity depends on genotype, composition of growth media, plant growth regulators (PGRs), and other organic substances (Karakas, 2020). Several studies have tested various culture media for goji (Fira et al., 2016; Tabăra, 2017; Karakas, 2020; Kruczek et al., 2020b). Although in vitro culture methods and conditions are similar for different goji genotypes, their requirements of growth regulators in culture media are different. Hence, it is important to develop a highly efficient plant regeneration system for each genotype.

This study aimed to develop a reliable protocol for in vitro shoot culture of goji by using different culture media (MS - Murashige and Skoog, 1968; WPM - Woody Plant Media Llyod and McCown, 1981; RA Anderson Rhododendron Medium; Anderson, 1984) with the addition of meta-Topolin ((6-(3hydroxybenzyloamino)-purine) for in vitro shoot multiplication of two cultivars of goji, namely 'No 1 ' and 'New Big. This study also evaluated in vitro and ex vitro rooting. Optimal medium, auxin requirement, and chitosan treatment were identified for rooting of the two goji cultivars.

\section{Materials and Methods}

\section{Plant material}

Two cultivars of goji, 'No 1' and 'New Big', which were taken from the orchard of the Department of Horticulture West Pomeranian University of Technology Szczecin, Poland, and used as biological material. The orchard is located in subzone 7A in the North-Western part of Poland in the Szczecin Lowland at a distance of approximately $65 \mathrm{~km}$ from the Baltic Sea $\left(53^{\circ} 400^{\prime} \mathrm{N}, 14^{\circ} 880^{\prime} \mathrm{E}\right)$. The research was conducted at a production plantation specializing in the cultivation of highbush blueberry. Goji cultivar 'New Big' is distinguished by large fruit with a length of $2 \mathrm{~cm}$ and width of $1 \mathrm{~cm}$. In 2013, in Poland was selected in the first variation of the sweet fruit without seeds ('No 1').

\section{Multiplication and culture conditions}

Shoots of about $2 \mathrm{~cm}$ of two Lycium chinense: 'No 1' and 'New Big' were taken in May 2019, as primary explants from 8-year shrubs cultivated in the orchard. An axillaries bud of goji was taken from sterile stabilized in vitro culture. The shoot explants were transferred to MS medium with the addition of meta-Topolin in a concentration of $0.0,0.4,0.6$, and $0.8 \mathrm{mg} \mathrm{L}^{-1}$; WPM and RA medium without addition of meta-Topoiln $(\mathrm{mT})$. Each combination included 48 shoots (6 shoots per flask in eight replication). All media were supplemented with $30 \mathrm{~g} \mathrm{~L}^{-1}$ sucrose (Chempur, Poland) and $100 \mathrm{mg} \mathrm{L}^{-1}$ myo-inositol (Duchefa, The Netherlands) and were solidified with $8 \mathrm{~g} \mathrm{~L}^{-1}$ agar (Biocorp, Poland), $\mathrm{pH}$ of the media was adjusted to 5.7. The media were heated and $30 \mathrm{ml}$ were poured into a $450 \mathrm{ml}$ flask and next they were autoclaved at $121^{\circ} \mathrm{C}(0.1 \mathrm{MPa})$ during the time required according to the volume of medium in the vessel. All cultures were incubated in a growth room at a temperature of $24 \pm 2{ }^{\circ} \mathrm{C}$ under 16 hours photoperiod with a photosynthetic flux density (PPFD) of $40 \mu \mathrm{mol}$ $\mathrm{m}^{-2} \mathrm{~s}^{-1}$ provided by Narva (Germany) emitting daylight cool white. After the end of the experimental period 
(five weeks), explants were removed and washed with deionized distilled water, and the lengths of the shoots and roots, the number of shoots per plant were measured, and shoot regeneration rate (\%) was estimated. The plants were weighed for calculated of plant fresh mass.

\section{In vitro and ex vitro rooting}

Shoots of 'No 1' and 'New Big', multiplied for four subcultures on MS containing $0.6 \mathrm{mg} \mathrm{L}^{-1} \mathrm{mT}$ or WPM, were transferred to a rooting inducing medium MS, MS with the addition of chitosan $(\mathrm{CH})$ at molecular weight $10 \mathrm{kDa}$ at a concentration of $20 \mathrm{ppm}$ (Bartkowiak, 2001), MS with auxins NAA ( $\alpha$ Naphthalene acetic acid) and IAA (3-Indoleacetic acid) at concentration 0.5 and $1.0 \mathrm{mg} \mathrm{L}^{-1}$. The culture condition was the same as at the multiplication stage. The length of the shoots and roots, and the number of roots per plant, as well as the mass of the plants, were calculated 35 days after the transferring to the rooting media.

Rooting shoots were transferred under the plastic tunnel to a mixture of $90 \%$ peat and $10 \%$ perlite with $90 \%$ of humidity for 2 weeks ( $\mathrm{pF}$ 1.7-2.1). Then, plants were transferred to the greenhouse. Survival rate (\%) was evaluated 3 months after the beginning of the acclimatization.

\section{Statistical analysis}

All statistical analyses were performed using Statistica 13.0 (StatSoft, Cracow, Poland). Statistical significance of the differences between means was determined by testing the homogeneity of variance and normality of distribution, followed by ANOVA with Tukey's post hoc test. The significance was set at $p<0.05$. To determine the relationship between the in vitro propagation and rooting for morphological traits, the results obtained were subjected to agglomerative cluster analysis and classified in a hierarchical order using Ward's method.

\section{Results and Discussion}

There are no reports describing the application of meta-Topolin in in vitro shoot multiplication of goji plants. According to Bairu et al. (2007), naturally occurring cytokinins such as $m$ T play an important role in retarding plant aging, increasing photosynthetic pigments, modulating antioxidant enzyme activity, and thereby improving root and shoot development. In our study, among the combinations of growth medium tested to induce shoot regeneration, WPM medium and MS with $m \mathrm{~T}$, yielded the best shoot regeneration rate from $92 \%$ to $97 \%$ in both goji 'No 1' and 'New Big' (Table 1). No significant differences were observed between the regeneration rate obtained for goji explants propagated on MS and RA medium, which was $68 \%$ to $72 \%$ for the two tested cultivars.

In both cases, the regeneration rate was higher than that obtained by Fira et al. (2016) for Lycium barbarum 'Ningxia N1', and by Tabăra (2017) for L. barbarum. Our results showed that WPM was the best medium for stimulating shoot length and the development of adventitious buds of goji. Compared to other culture media used, goji grown on WPM showed higher length of shoots $(3.99$ and $4.12 \mathrm{~cm}$, for 'No 1' and 'New Big', respectively) (Table 1). The addition of $m$ T to MS medium increased the average shoot length as compared to that obtained MS and RA medium. When MS was supplemented with $0.6 \mathrm{mg} \mathrm{L}^{-1} \mathrm{mT}$, the maximum shoot length for 'No 1' and 'New Big' was 3.61 and $3.53 \mathrm{~cm}$, respectively. Moreover, shoot culture of goji 'No 1' on MS with the addition of $0.6 \mathrm{mg} \mathrm{L}^{-1} \mathrm{mT}$ resulted in higher number of shoot formation (1.50 and 1.42 shoot/plant, 'No 1' and 'New Big', respectively). It was observed that plants of both cultivars grown on WPM and MS media with $m$ T supplementation showed an increase in fresh weight from $7 \%$ to $33 \%$ as compared to that noted for the other culture media combinations used (MS and RA). To summarize, $m \mathrm{~T}$ and WPM medium positively stimulated the growth and development of adventitious shoots of goji. These findings agree with Bairu et al. (2007) and Gentile et al. (2014) who obtained better results for micropropagation of 
Aloe polyphylla and Prunus, respectively, in culture medium supplemented with $m$ T relative to BA. According to Naaz et al. (2019), an increase in growth parameters of explants treated with $m$ T may be due to positive signalling in dormant meristematic cells to form new shoots by maintaining juvenility in plant tissues.

A cluster analysis conducted using Ward's method (Figure 1a) showed three separate groups with a similar influence on the multiplication of goji 'No 1' and 'New Big. The analysis showed that the shoots of both cultivars collected from WPM and MS with supplemented with $m$ T had a similar regeneration rate.

Table 1. The influence of various medium on the morphological traits and regeneration rate in vitro of $L$. chinense 'No 1' and 'New Big'

\begin{tabular}{|c|c|c|c|c|}
\hline Treatments & Shoots length $[\mathrm{cm}]$ & No of shoots per explant & $\begin{array}{c}\text { Fresh weight } \\
{[\mathrm{g}]}\end{array}$ & $\begin{array}{c}\text { Shoot regeneration } \\
\text { rate }[\%]\end{array}$ \\
\hline \multicolumn{5}{|c|}{ 'No 1' } \\
\hline MS & $3.18 \mathrm{abc}^{*}$ & $1.17 \mathrm{ab}$ & $0.445 \mathrm{ab}$ & 71 \\
\hline $\mathrm{MS}+0.4 \mathrm{mg} \mathrm{L}^{-1} \mathrm{mT}$ & $2.89 \mathrm{ab}$ & $1.25 \mathrm{abc}$ & $0.576 \mathrm{~cd}$ & 92 \\
\hline $\mathrm{MS}+0.6 \mathrm{mg} \mathrm{L}^{-1} \mathrm{mT}$ & $3.61 \mathrm{bcd}$ & $1.50 \mathrm{cb}$ & $0.598 \mathrm{de}$ & 96 \\
\hline $\mathrm{MS}+0.8 \mathrm{mg} \mathrm{L}^{-1} \mathrm{mT}$ & $3.27 \mathrm{abc}$ & $1.33 \mathrm{abc}$ & $0.483 \mathrm{abc}$ & 95 \\
\hline WPM & $3.99 \mathrm{~cd}$ & $1.42 \mathrm{bc}$ & $0.529 \mathrm{abcd}$ & 97 \\
\hline RA & $3.24 \mathrm{abc}$ & $1.25 \mathrm{abc}$ & $0.457 \mathrm{ab}$ & 68 \\
\hline \multicolumn{5}{|c|}{ 'New Big' } \\
\hline MS & $2.71 \mathrm{a}$ & $1.00 \mathrm{a}$ & $0.426 \mathrm{a}$ & 68 \\
\hline $\mathrm{MS}+0.4 \mathrm{mg} \mathrm{L}^{-1} \mathrm{mT}$ & $2.83 \mathrm{ab}$ & $1.33 \mathrm{abc}$ & $0.493 \mathrm{abcd}$ & 93 \\
\hline $\mathrm{MS}+0.6 \mathrm{mg} \mathrm{L}^{-1} \mathrm{mT}$ & $3.53 \mathrm{abcd}$ & $1.42 \mathrm{bc}$ & $0.581 \mathrm{~cd}$ & 95 \\
\hline $\mathrm{MS}+0.8 \mathrm{mg} \mathrm{L}^{-1} \mathrm{mT}$ & $3.36 \mathrm{abcd}$ & $1.33 \mathrm{abc}$ & $0.694 \mathrm{e}$ & 95 \\
\hline WPM & $4.12 \mathrm{~d}$ & $1.58 \mathrm{c}$ & $0.549 \mathrm{bcd}$ & 97 \\
\hline RA & $3.42 \mathrm{abcd}$ & $1.25 \mathrm{abc}$ & $0.444 \mathrm{ab}$ & 72 \\
\hline
\end{tabular}

Means followed by the same letter do not differ significantly at $P=0.05$ according to Tukey multiple range

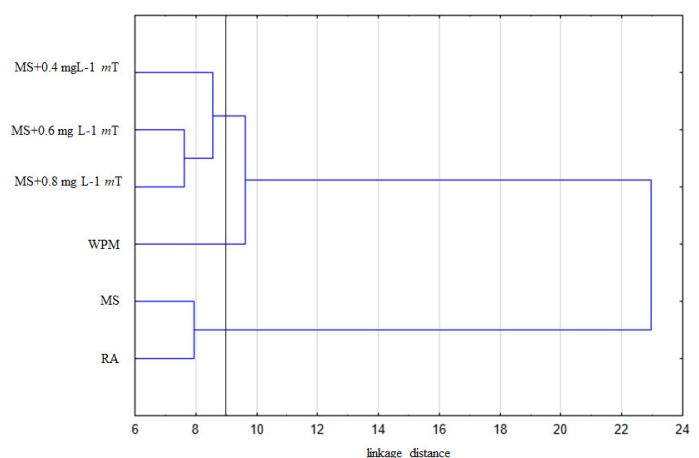

(a)

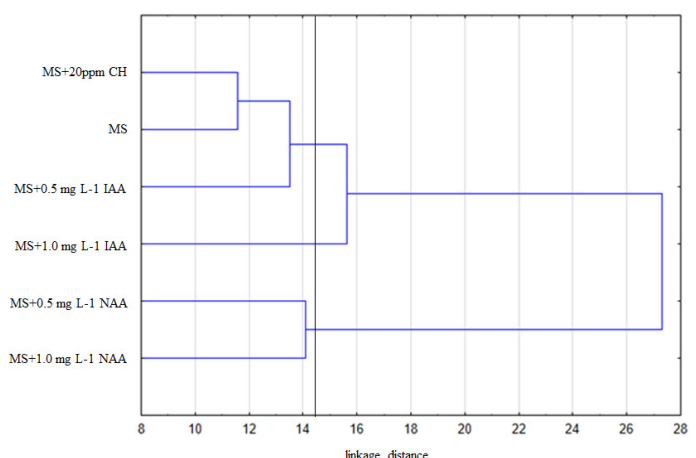

(b)

Figure 1. Dendrogram of cluster analysis for propagation (a) and rooting (b) of two goji cultivars 'No 1' and 'New Big' under in vitro culture. The vertical line (linkage distance 9 and 14.5 , respectively) indicates the cut-off used to form the groups

The effect of chitosan on the rooting of goji plants remains unelucidated, hence, we conducted an experiment to compare the efficacy of chitosan and the auxins IAA and NAA in in vitro rooting. Chitosan is an eco-friendly biopolymer, it is derived from chitin and shows good biodegradability, bioactivity, and biocompatibility (Krupa-Małkiewicz and Fornal, 2018). In the current study, NAA, IAA, and chitosan showed quite different effects on the two goji cultivars tested in in vitro shoot rooting (Table 2, Figure 2a, b). It was observed, that MS medium supplemented with $20 \mathrm{ppm}$ chitosan was optimal for the initiation of rhizogenesis 
of goji plantlets, with the longest shoots ( 7.25 and $6.87 \mathrm{~cm}$ for 'No 1' and 'New Big', respectively), and roots (4.71 and $4.91 \mathrm{~cm}$ for 'No 1' and 'New Big', respectively) and the highest number of roots per plant (2.58). Moreover, the plants were more robust and better rooted, thus reducing labor requirements. No significant differences were observed when plantlets were rooted on MS supplemented with IAA, independent of its concentration. Moreover, plantlets rooted on MS with chitosan and MS with IAA had higher fresh mass (from $186 \%$ to $287 \%)$ than the control plantlets $(0.222 \mathrm{~g})$. However, plantlets obtained from treatment with NAA had smaller roots and lower number of roots per plant, which was similar to the control plants (MS) of both the tested cultivars (Table 2, Figure 2a, b).

Table 2. In vitro rooting capacity and ex vitro rooting rate of $L$. chinense 'No 1' and 'New Big'

\begin{tabular}{|c|c|c|c|c|c|}
\hline Treatments & $\begin{array}{c}\text { Shoot lenght } \\
{[\mathrm{cm}]}\end{array}$ & $\begin{array}{l}\text { Root lenght } \\
{[\mathrm{cm}]}\end{array}$ & $\begin{array}{l}\text { No of roots } \\
\text { per explant }\end{array}$ & $\begin{array}{c}\text { Fresh weight } \\
{[\mathrm{g}]}\end{array}$ & $\begin{array}{c}\text { Ex vitro rooting } \\
\text { rate }[\%]\end{array}$ \\
\hline \multicolumn{6}{|c|}{ 'No 1' } \\
\hline MS & $2.98 \mathrm{bc}^{*}$ & $2.25 \mathrm{~d}$ & $1.33 \mathrm{~b}$ & $0.222 \mathrm{a}$ & 20 \\
\hline $\mathrm{MS}+20 \mathrm{ppm} \mathrm{CH}$ & $7.25 \mathrm{~d}$ & $4.71 \mathrm{e}$ & $2.58 \mathrm{c}$ & $0.637 \mathrm{cde}$ & 80 \\
\hline $\mathrm{MS}+0.5 \mathrm{mg} \mathrm{L}-1 \mathrm{NAA}$ & $2.99 \mathrm{bc}$ & $2.32 \mathrm{~d}$ & $2.50 \mathrm{c}$ & $0.547 \mathrm{~cd}$ & 20 \\
\hline $\mathrm{MS}+1.0 \mathrm{mg} \mathrm{L}-1 \mathrm{NAA}$ & $3.13 \mathrm{bc}$ & $2.03 \mathrm{~cd}$ & $2.25 \mathrm{bc}$ & $0.490 \mathrm{bc}$ & 20 \\
\hline $\mathrm{MS}+0.5 \mathrm{mg} \mathrm{L}-1 \mathrm{IAA}$ & $4.27 \mathrm{c}$ & $4.37 \mathrm{e}$ & $2.83 \mathrm{c}$ & $0.706 \mathrm{cde}$ & 75 \\
\hline $\mathrm{MS}+1.0 \mathrm{mg} \mathrm{L}-1 \mathrm{IAA}$ & $3.88 \mathrm{c}$ & $4.39 \mathrm{e}$ & $2.25 \mathrm{bc}$ & $0.700 \mathrm{cde}$ & 70 \\
\hline \multicolumn{6}{|c|}{ 'New Big' } \\
\hline MS & $3.76 \mathrm{c}$ & $2.58 \mathrm{~d}$ & $1.50 \mathrm{~b}$ & $0.239 \mathrm{a}$ & 20 \\
\hline $\mathrm{MS}+20 \mathrm{ppm} \mathrm{CH}$ & $6.87 \mathrm{~d}$ & $4.91 \mathrm{e}$ & $2.58 \mathrm{c}$ & $0.677 \mathrm{cde}$ & 70 \\
\hline $\mathrm{MS}+0.5 \mathrm{mg} \mathrm{L}-1 \mathrm{NAA}$ & $2.02 \mathrm{ab}$ & $1.13 \mathrm{bc}$ & $1.50 \mathrm{~b}$ & $0.732 \mathrm{de}$ & 0 \\
\hline $\mathrm{MS}+1.0 \mathrm{mg} \mathrm{L}-1 \mathrm{NAA}$ & $1.33 \mathrm{a}$ & $0.52 \mathrm{ab}$ & $0.25 \mathrm{a}$ & $0.542 \mathrm{~cd}$ & 0 \\
\hline $\mathrm{MS}+0.5 \mathrm{mg} \mathrm{L}-1 \mathrm{IAA}$ & $4.10 \mathrm{c}$ & $4.41 \mathrm{e}$ & $2.08 \mathrm{bc}$ & $0.746 \mathrm{de}$ & 60 \\
\hline $\mathrm{MS}+1.0 \mathrm{mg} \mathrm{L}-1 \mathrm{IAA}$ & $3.79 c$ & $4.37 \mathrm{e}$ & $2.25 \mathrm{bc}$ & $0.859 \mathrm{e}$ & 60 \\
\hline
\end{tabular}

Previous studies on this topic have shown that chitosan addition to the medium has varied influence on the morphology of different plant species. Ait Barka et al. (2004), used chitogel to stimulate the growth of grapevine in vitro, and showed that concentrations of over $2 \%(\mathrm{v} / \mathrm{v})$ chitogel had a negative effect on plant growth, based on shoot-length measurements. Sopalun et al. (2010) suggested that chitosan promoted in vitro shoot formation of Grammatophyllum speciosum but not rooting. In contrast, Krupa-Małkiewicz and Fornal (2017) showed the stimulating effect of chitosan on the morphology and rooting of Petunia $x$ atkinsana propagated in vitro. Our results on in vitro rooting of $L$. chinense on MS medium supplemented with chitosan are novel in the field of goji rooting.

Direct ex vitro rooting of goji 'No 1' and 'New Big' shoots from MS + 20 ppm chitosan and MS + IAA in the greenhouse was 60-80\% efficient (Table 2, Figure 2c, d). The rooting efficiency of goji 'No 1' shoots on MS supplemented with NAA was the lowest $(20 \%)$ and similar to that for the control plants (Table 2). Explants of 'New Big' shoots rooted on MS supplemented with NAA did not survive. Rooting treatment with chitosan yielded good results for all the parameters studied; the plantlets were more robust and better rooted, thus reducing labour requirements. 


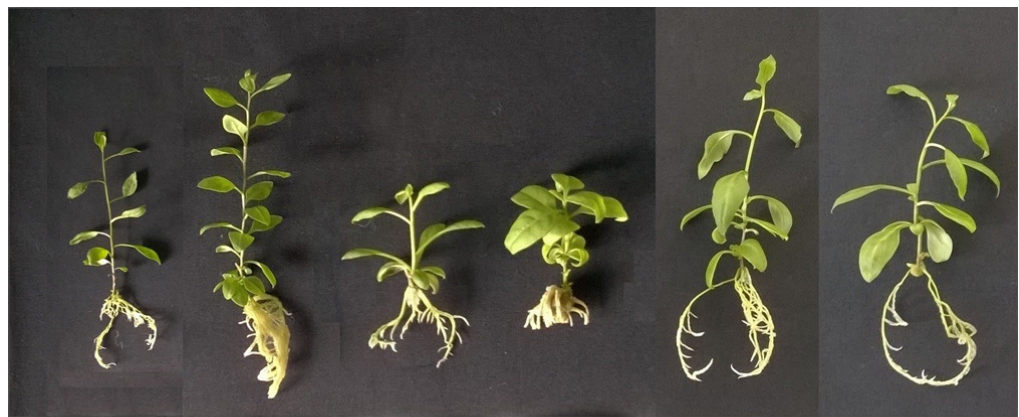

MS

$\mathrm{MS}+20 \mathrm{ppm} \mathrm{CH}$

MS +0.5 mgL- 1 NAA MS +1.0 mgl- 1 NAA MS +0.5 mgL- 1 IAA

MS $+1.0 \mathrm{mgL}-1$ IAA

(a)

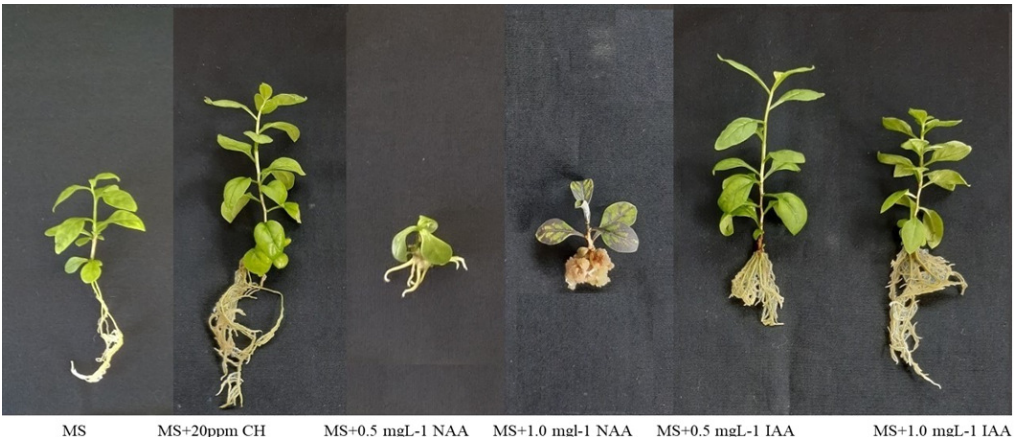

(b)

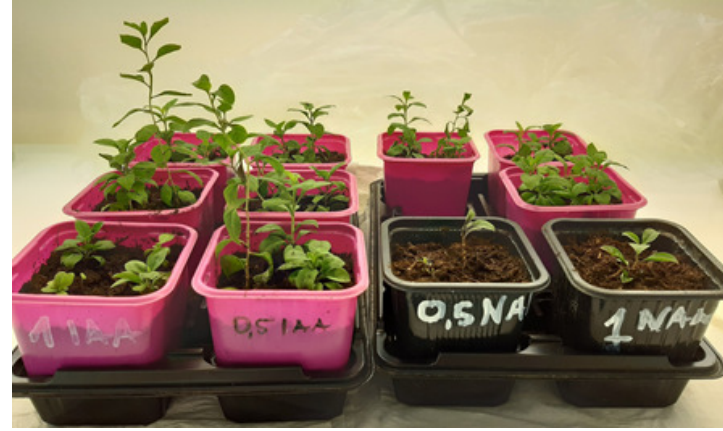

(c)

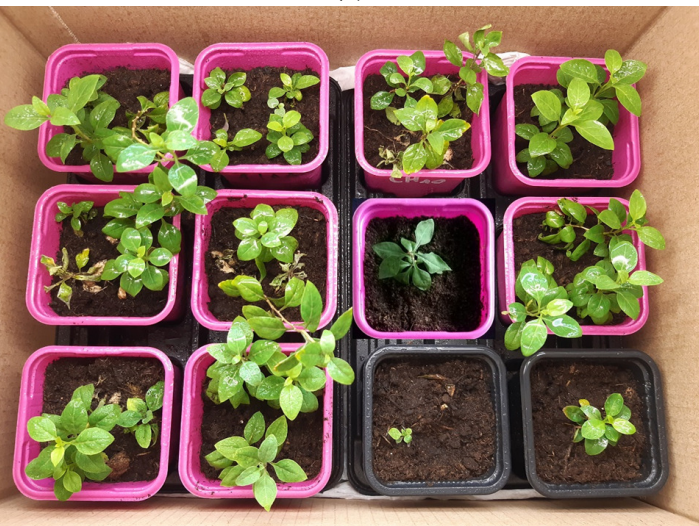

(d)

Figure 2. In vitro rooting of goji 'No 1' (a) and 'New Big' (b) on different rooting medium. Plants acclimatized after 35 days after the transferring to the greenhouse 'No 1' - (c) and 'New Big' - (d) 
A cluster analysis conducted using Ward's method (Figure 1b) showed three separate groups (a-c) with a similar influence of medium composition on the in vitro rooting of goji 'No 1' and 'New Big'.

Silvestri et al. (2018) showed that the percentage of rooted shoots of L. barbarum 'Nixia 1' was higher $(87-95 \%)$ in $1 / 2$ MS with $1 \%$ sucrose and indole butyric acid (IBA) with or without putrescine and the acclimatization rate of the plants in soil range from $88.7 \%$ to $95.1 \%$. Tabăra (2017) rooted L. barbarum (boxthorn) with a higher success rate (90-95\%) of explants transferred to a solid substrate of peat and sand. Fira et al. (2016) recommended floatation hydroculture for ex vitro acclimatization of L. barbarum cultivar Ningxia N1 on the basis of the high survival percentage obtained (90\%).

\section{Conclusions}

In conclusion, we developed a complete micropropagation protocol for $L$. chinense cultivars 'No 1 ' and 'New Big. MS medium supplemented with meta-Topolin in the concentration of $0.6 \mathrm{mg} \mathrm{L}^{-1}$ and WPM medium without plant growth regulators show good results in terms of rapid multiplication and growth of goji shoots. Media supplemented with $20 \mathrm{ppm}$ of chitosan also proved to be very effective, as they provided high rooting rates (70-80\%) and well-developing plantlets. For ex vitro acclimatization, the mixture of $90 \%$ peat and $10 \%$ perlite with high humidity (90\%) was effective for goji 'No 1' and 'New Big' cultivars. The results obtained may be useful to improve the efficiency of micropropagation and rooting of goji.

\section{Authors' Contributions}

Conceptualization: MK-M; Data curation: AK, MK-M; Formal analysis: AK, MK-M, IO; Funding acquisition: AK, MK-M, IO; Investigation: AK, MK-M; Methodology: MK-M, AK; Supervision: IO; Writing - original draft: MK-M, AK; Writing - review and editing: MK-M, IO. All authors read and approved the final manuscript.

\section{Acknowledgements}

This work was supported by the West Pomeranian University of Technology, Szczecin, grant number 518-07-014-3171-03/18.

\section{Conflict of Interests}

The authors declare that there are no conflicts of interest related to this article.

\section{References}

Ait Barka E, Eullaffroy P, Clément C, Vernet G (2004). Chitosan improves development, and protects Vitis vinifera L. against Botrytis cinerea. Plant Cell Reports 22:608-614. https://doi.org/10.1007/s00299-003-0733-3

Anderson WC (1984). A revised tissue culture medium for shoot multiplication of rhododendron. Journal of the American Society for Horticultural Science 109(3):343-347.

Bairu MW, Stirk WA, Dolezal K, Van Staden J (2007). Optimizing the micropropagation protocol for the endangered Aloe polyphylla: can meta-topolin and its derivatives serve as replacement for benzyladenine and zeatin?. Plant Cell, Tissue and Organ Culture 90(1):15-23. https://doi.org/10.1007/s11240-007-9233-4 
Bartkowiak A (2001). Binary polyelectrolyte microcapsules based on natural polysaccharides. Edt. PS Szczecin.

Dănăilă-Guidea SM, Dobrinoiu RV, Vişan L, Toma RC (2015). Protocol for efficient in vitro multiplication of Lycium barbarum L.(goji) by direct organogenesis. Scientific Bulletin. Series F. Biotechnologies 19:34-38.

Fira A, Joshee N, Cristea V, Simu M, Hârța M, Pamfil D, Clapa D (2016). Optimization of micropropagation protocol for goji berry (Lycium barbarum L.). Bulletin of the University of Agricultural Sciences \& Veterinary Medicine Cluj-Napoca. Horticulture 73(2). https://doi.org/10.15835/buasvmcn-hort:12177

Gentile A, Gutiérrez MJ, Martinez J, Frattarelli A, Nota P, Caboni E (2014). Effect of meta-Topolin on micropropagation and adventitious shoot regeneration in Prunus rootstocks. Plant Cell, Tissue and Organ Culture (PCTOC) 118(3):373-381. https://doi.org/10.1007/s11240-014-0489-1

Karakas FP (2020). Efficient plant regeneration and callus induction from nodal and hypocotyl explants of goji berry (Lycium barbarum L.) and comparison of phenolic profiles in calli formed under different combinations of plant growth regulators. Plant Physiology and Biochemistry 146:384-391. https://doi.org/10.1016/j.plaphy.2019.11.009

Kruczek A, Ochmian I, Krupa-Małkiewicz M, Lachowicz S (2020a). Comparison of morphological, antidiabetic and antioxidant properties of goji fruits. Acta Universitatis Cibiniensis. Series E: Food Technology 24(1):1-14. https://doi.org/10.2478/aucft-2020-0001

Kruczek A, Ochmian I (2016). The influence of shrubs cutting method on yielding and quality of the goji berries (Lycium barbarum L.). Folia Pomeranae Universitatis Technologiae Stetinensis. Agricultura, Alimentaria, Piscaria et Zootechnica 40(4 (330)):131-138. https://doi.org/10.2478/aucft-2020-0001

Kruczek A, Krupa-Małkiewicz M, Lachowicz S, Oszmiański J, Ochmian I (2020b). Health-promoting capacities of in vitro and cultivated goji (Lycium chinense Mill.) fruit and leaves; polyphenols, antimicrobial activity, macro-and microelements and heavy metals. Molecules 25(22):5314. https://doi.org/10.3390/molecules25225314

Krupa-Małkiewicz M, Fornal N (2018). Application of chitosan in vitro to minimize the adverse effects of salinity in Petunia $\times$ atkinsiana D. don. Journal of Ecological Engineering 19(1). https://doi.org/10.12911/22998993/79410

Kulczyński B, Gramza-Michałowska A (2016). Goji berry (Lycium barbarum): composition and health effects-a review. Polish Journal of Food and Nutrition Sciences 66(2):67-76. https://doi.org/10.1515/pjfns-2015-0040

Lloyd G, McCown B (1980). Commercially feasible micropropagation of mountain laurel, Kalmia latifolia, by use of shoot-tip culture. Combined Proceedings of International Plant Propagators' Society 30:421-427.

Murashige T, Skoog F (1962). A revised medium for rapid growth and bioassay with tobacco tissue culture. Physiologia Plantarum 15:473-497.

Sá RR, da Cruz Caldas J, de Andrade Santana D, Lopes MV, Dos Santos WNL, Korn MGA, Júnior ADFS (2019). Multielementar/centesimal composition and determination of bioactive phenolics in dried fruits and capsules containing Goji berries (Lycium barbarum L.). Food Chemistry 273:15-23. https://doi.org/10.1016/j.foodchem.2018.05.124

Silvestri C, Sabbatini G, Marangelli F, Rugini E, Cristofori V (2018). Micropropagation and ex vitro rooting of Wolfberry. HortScience 53(10):1494-1499. https://doi.org/10.21273/HORTSCI13423-18

Sopalun K, Thammasiri K, Ishikawa K (2010). Effects of chitosan as the growth stimulator for Grammatophyllum speciosum in vitro culture. International Journal of Innovative Research in Science Engineering Technology $4(11): 828-830$.

Tabăra GM (2017). Aspects of the in vitro organogenesis of the species Lycium barbarum L. (Goji). Revista Botanică $14(1): 29-34$.

Naaz A, Hussain SA, Anis M, Alatar AA (2019). Meta-topolin improved micropropagation in Syzygium cumini and acclimatization to ex vitro conditions. Biologia Plantarum 63(1):174-182. https://doi.org/10.32615/bp.2019.020

Wojdyło A, Nowicka P, Bąbelewski P (2018). Phenolic and carotenoid profile of new goji cultivars and their antihyperglycemic, anti-aging and antioxidant properties. Journal of Functional Foods 48:632-642. https://doi.org/10.1016/j.jff.2018.07.061 
OPEN ACCESS

(c) (2)

The journal offers free, immediate, and unrestricted access to peer-reviewed research and scholarly work. Users are allowed to read, download, copy, distribute, print, search, or link to the full texts of the articles, or use them for any other lawful purpose, without asking prior permission from the publisher or the author.

License - Articles published in Notulae Botanicae Horti Agrobotanici Cluj-Napoca are Open-Access, distributed under the terms and conditions of the Creative Commons Attribution (CC BY 4.0) License. (C) Articles by the authors; UASVM, Cluj-Napoca, Romania. The journal allows the author(s) to hold the copyright/to retain publishing rights without restriction. 